\title{
Insecticide-treated nets usage and malaria episodes among boarding students in Zaria, northern Nigeria
}

\author{
A. A. Aliyu, M. Alti-Mu'azu \\ Department of Community Medicine, A.B.U., Zaria, Nigeria
}

Page | 85

Correspondenceto: Dr. A. A. Aliyu, Department of Community Medicine, A.B.U., Zaria, Nigeria.

E-mail: draaaliyu@yahoo.com

\begin{abstract}
Background: Despite malaria being the largest public health problem in Africa South of Sahara with over one million associated deaths each year, there has been little progress in its prevention/control during the past decades. Therefore, this study was conducted to determine the knowledge, attitude, use of insecticide-treated nets (ITNs), and the prevalence of malaria episodes among boarding secondary school pupils in Zaria, Nigeria.

Methods: A multi-stage sampling technique was used to sample five (5) secondary schools within Zaria, from which six classes (JSS 1 - 3 and SS 1- 3) of respondents were then randomly selected. Structured, closed-ended selfadministered questionnaires were used to collect information on demographic characteristics, knowledge, attitude, and use of ITNs, reasons for non-use and malaria episodes in last 12 months.

Results: A total of 150 students from the five (5) boarding secondary schools were interviewed, majority were in the age group $15-17(53.3 \%)$ with a mean $(x) \pm S D$ of $16.8 \pm 0.8$ years. Males were $60 \%$ and females $40 \%$ of respondents. Majority of the respondents (87.3\%) knew about and had actually seen an ITN; only $43.3 \%$ were current users. Most of the current users of ITN noticed a significant reduction in malaria episodes in the last 12 months. This was statistically significant $(P=0.004)$. Cost and availability were reasons sited by non-ITN users.

Conclusion: There is urgent need on the part of all the three tiers of Government for public health awareness campaigns through information, education and communication (IEC) to create positive ITN culture and usage. It is also suggested that ITN usage among boarding school pupils should be incorporated into school health service.
\end{abstract}

Keywords: Boarding schools, ITN use and malaria episodes, Nigeria, students

\section{Résumé}

arrière-plan: malgré le paludisme est la plus grand problème de santé en Afrique au sud du Sahara avec plus d'un million associé de décès chaque année, sa prévention a été peu de progrès contrôle au cours des dernières décennies 1. C'est pourquoi cette étude a été menée à déterminer les connaissances, attitude, utilisation de moustiquaires insecticide traité et de la prévalence des épisodes de paludisme parmi l'embarquement des écoles secondaires à Zaria, au Nigéria.

méthodes: technique d'échantillonnage de plusieurs utilisée pour l'échantillon cinq (5) les écoles secondaires au sein de Zaria, depuis les six (6) classes (JSS 1-3 et SS 1-3) des répondants ont été sélectionnés puis au hasard. Structurée, fermées questionnaires auto-administrés ont servi à recueillir des informations sur caractéristiques démographiques, connaissances, attitude et l'utilisation de moustiquaires imprégnées filets [MII], raisons d'épisodes de non utilisation et le paludisme dans 12 derniers mois.

résultats: au total, une centaine de et cinquante (150) étudiants depuis les cinq (5) d'embarquer des écoles secondaires ont été interrogés, la majorité étaient dans le groupe d'âge 15-17 (53.3\%) avec un \pm moyenne (x) SD de \pm 67.9 ans 0,8 . Les garçons étaient $60 \%$ et les femelles $40 \%$ des répondants. Majorité des intimés (87,3\%) étaient au courant et avait réellement vu une MII; seulement $43.3 \%$ étaient des utilisateurs actuels. La plupart des utilisateurs actuels de MII remarqué une importante réduction de la malaria épisodes dans les 12 derniers mois. c'était statistiquement significative $(P=0,004)$. Coût et disponibilité étaient raisons placés par les MII les utilisateurs.

conclusion: il est urgent sur la partie de tous les 3 niveaux du gouvernement de campagnes de sensibilisation de santé publique par le biais d'informations, l'éducation et communication [IEC] pour créer les MII positive la culture 
et l'utilisation. C'est aussi suggéré que l'utilisation de MII parmi pensionnat les élèves devraient être intégrées à service de santé scolaire.

Mots cles: des écoles privées Les élèves, utilisent les MII et le paludisme épisodes, Nigeria

DOI: $10.4103 / 1596-3519.56234$

PMID: 19805937

Page $\mid 86$

\section{Introduction}

Malaria has reached, a global crisis now kills at least one million people each year, about 3000 a day, and 9 out of 10 cases occur in Africa south of Sahara. It also kills a child every 30s. ${ }^{[1]}$ Malaria has many negative effects on its victims; on productivity for example, it worsens the poverty of African nations by preventing adults from working, as patients can be ill for 5-20 days at a time. Malaria prevents children from learning and the cost of malaria control and treatment drains African economies. ${ }^{[2]}$ It is unfortunate that the cheapest malaria drug, chloroquine is rapidly losing its pharmacological effectiveness in almost all endemic countries. Similarly, in some parts of the world, strains of malaria have developed resistance to the four leading anti-malarial drugs. ${ }^{[1]}$ Consequently, strategic plans for rolling back malaria have to be developed. These include the use of insecticidetreated nets (ITNs) in many African countries, especially by the more vulnerable group---pregnant women and children. ITNs are a practical malaria control tool with proven efficacy that are easy to use and are currently the only viable option in malaria prevention in many African countries. The target population of this study was selected because they are mostly children (a vulnerable group), between the ages of 13 and 18, and are boarding in Secondary schools in Zaria, Nigeria (an endemic area). These children need protection from the scourges of malaria, which can lead to sickness absenteeism and loss of valuable academic time required for intellectual development.

\section{Materials and Methods}

The study was undertaken in Zaria and Sabon Gari Local Government Areas in Kaduna State of Nigeria, where the five boarding secondary schools were located.

Zaria has a tropical continental climate with a rainfall pattern that is typical of tropical guinea savannah. It has distinct wet and dry seasons and mean annual rainfall of about $1,075 \mathrm{~mm}$. There are five main settlements in Zaria: Zaria City (the traditional city), Tudun Wada, Sabon Gari, Hanwa and Samaru with a total population of over $1,490,000 .^{[3]}$
The list of the schools was obtained from 1991 Census Population of Kaduna State. ${ }^{[3]}$ In each school, structured questionnaires with close-ended questions were self-administered in order to collect data on demographic characteristics, knowledge attitude, and use of ITNs, reasons for non-use and malaria episodes in the last 12 months. Respondents were given 30 min training on how to properly complete the questionnaires in order to ensure accuracy and correct answers to the questions. At the end of the exercise, the hostels in all the five schools were physically inspected for environmental cleanliness---clear drainages, mosquito breeding sites, presence/absence of nets in the windows etc. Permission to carry out the research was obtained through written communication to the Principals of the respective schools and informed consent of the study participants. Data were analyzed using the SPSS statistical software package. Statistical methods used included frequency.

\section{Results}

A total of 150 students from the five boarding secondary schools (30 each) were interviewed. Majority (53.3\%) were in the age group 15-17 with a mean $(\mathrm{x}) \pm \mathrm{SD}$ of $16.8 \pm 0.8$ years. Thirty-two percent $(32 \%)$ were in the age range of $18-20$ years, as shown in Table 1 . Sex distribution showed that males were $60 \%$ and females $40 \%$, respectively, giving a sex ratio of 1.5 . Majority of the respondents (87.3\%) knew about and had actually seen an ITN. Most of respondents also knew and correctly identified the vulnerable group targeted for ITN use. Only $43.3 \%$ are current ITN users. Sex distribution of current users showed males (38.9\%) and females (50\%), respectively, [Tables 2-4]. Most of the current users of ITN reported a marked reduction in frequency of clinical episodes of malarial attack. Users of ITN reported 74 episodes of malaria compared to 168 episodes among non-ITN users in the last 12 months. This was statistically significant $\left(\chi^{2}=25.5\right.$, $\mathrm{df}=1, \mathrm{P}=0.004)$ [Table 5, Figure 1].

Reasons given by non-users included among others were cost, availability of ITNs, heat, and inconvenient to sleep under it.

The school environment was quite neat, but a 


\begin{tabular}{|c|c|c|}
\hline Age group & Frequency & $\%$ \\
\hline $12-14$ & 18 & 12.0 \\
\hline $15-17$ & 80 & 53.3 \\
\hline $18-20$ & 48 & 32.0 \\
\hline $21-23$ & 4 & 2.7 \\
\hline Total & 150 & 100.0 \\
\hline \multicolumn{3}{|c|}{ Mean age $(x) \pm S D=16.8 \pm 0.8$} \\
\hline \multicolumn{3}{|c|}{ Gender characteristics } \\
\hline Males & 90 & 60 \\
\hline Females & 60 & 40 \\
\hline Total & 150 & 100 \\
\hline \multicolumn{3}{|c|}{ Table 2: Knowledge on insecticide-treated nets } \\
\hline Knowledge & Frequency & $\%$ \\
\hline Knew and seen ITN & 131 & 87.3 \\
\hline Knew but not seen ITN & 13 & 8.7 \\
\hline Don't know/seen ITN & 6 & 4.0 \\
\hline Total & 150 & 100.0 \\
\hline
\end{tabular}

lot needs to be done to maintain environmental aesthetics of the hostels.

\section{Discussion}

Malaria continues to be a major public health problem in many endemic countries and is one of the major causes of morbidity and mortality in subSaharan Africa. It is estimated that malaria causes about 300-500 million clinical cases, and 1.5-2.7 million deaths globally each year, with $80-90 \%$ of the clinical cases and one million deaths occurring in Africa alone. ${ }^{[4]}$

In Nigeria, malaria accounts for more than $60 \%$ of clinic attendance with over 500 million episodes occurring each year. ${ }^{[5]}$ In 2002 alone, 2.6 million cases and 4,092 deaths from malaria were recorded in the country ${ }^{[6]}$ Records on the use of mosquito nets date back to the sixth century B.C. They have been used for decades as protection against nuisance/ harmful insects, dust and roof debris falling on sleepers as well as for privacy. ${ }^{[4]}$ However, the application of insecticides to bed nets (mosquito nets) was first used by Russian troops during the Second World War. ${ }^{[7]}$

The potential epidemiological usefulness and public health benefits of ITNs for protection against malaria was reconsidered in the 1980s with the advent of the photo stable synthetic pyrethroids. ${ }^{[4]}$

The current $\mathrm{WHO}$ initiatives in malaria control such as roll back malaria (RBM) emphasizes the use of ITNs and environmental management to reduce
Table 3: Distribution of respondents by usage of ITN

\begin{tabular}{|c|c|c|c|}
\hline Usage & & Frequency & $\%$ \\
\hline Current users & & 65 & 43.3 \\
\hline Non-users & & 85 & 56.7 \\
\hline Total & & 150 & 100.0 \\
\hline \multicolumn{4}{|c|}{$\begin{array}{l}\text { Table 4: Distribution of current users and non- } \\
\text { users of insecticide-treated net by sex }\end{array}$} \\
\hline Users & Male & Female & Total \\
\hline Usage & 35 (38.9\%) & $30(50 \%)$ & 65 \\
\hline Non-usage & $55(61.1 \%)$ & 30 (50\%) & 85 \\
\hline Total & 90 & 60 & 150 \\
\hline
\end{tabular}

Table 5: Showing the relationship between ITN use and reported episodes of malaria among students

\begin{tabular}{lcc}
\hline Malaria episodes & \multicolumn{2}{c}{ ITN usage status } \\
\cline { 2 - 3 } last 12 months & $\begin{array}{c}\text { Current users } \\
(N=65)\end{array}$ & $\begin{array}{c}\text { Non-users } \\
(N=85)\end{array}$ \\
\hline $1-4$ & 42 & 19 \\
$5+$ & 23 & 66 \\
\hline
\end{tabular}

$\underline{\chi^{2}}=25.5, \mathrm{df}=1, P=0.004$, ITN: Insecticide-treated net

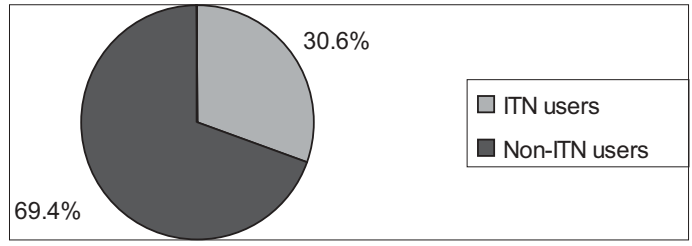

Figure 1: Distribution of outcome according to ability to do relevant investigations

the vector population as key strategies for malaria prevention and control in sub-Saharan Africa. ${ }^{[8,9]}$

The most promising and yet most tasking of the WHO strategies for malaria control is the provision and use of ITNs, which has been described as an important and popular tool for malaria control programme. ${ }^{[10]}$ They are, therefore, seen as one of the main tools of achieving RBM's objective of halving the world's malaria burden by the year 2010 . It also calls for a 30 -fold increase in the purchase and use of ITNs in Africa. ${ }^{[1]}$

The findings from this study revealed that knowledge and awareness of ITN among secondary school students was high (87.3\%). They are also aware of the vulnerable group that is being targeted for ITN use. However, usage of ITN among respondents was very low $(43.3 \%)$. When this number was extrapolated among the entire population of boarding students, the figure of current users was even lower. Again, assuming this was projected to the entire community of Zaria, the numbers of households using an ITN will be quite insignificant. This agrees with the study done at Kuje Area Council, Abuja where net use was 
found to be $32.9 \% \cdot{ }^{[12]}$ Even though it has been stated that ITN implementation in some communities in Nigeria has been very effective. ${ }^{[13]}$ Also, most of the current users (74) reported a marked reduction in malaria episodes compared to non-ITN users (168). This was statistically significant $(P=0.004)$. Cases of malaria episodes among ITN users may not be unconnected with improper use and/or torn nets. ${ }^{[14]}$ This is not surprising as studies have demonstrated the advantages of sleeping under ITNs. Apart from providing physical barrier against mosquito bites, ITNs are known to have mass killing effects and to protect against a wide range of vector-borne diseases and reduce childhood mortality by about $20 \%$ in Africa. ${ }^{[1114-16]}$ The cost of ITN, like cost of many public health goods continues to raise serious concern.

In this study, most of the non-users $(71.3 \%)$ the reason cited was cost. Even though the cost of ITN has been described as low ${ }^{[17]}$ its price ranges from N500-N2000 (US\$3.91-US\$15.63) which in Nigeria is still very high in view of the fact that more than $70 \%$ of Nigerians are currently living below the poverty line of less than US $\$ 1$ per day. ${ }^{[18,19]}$ This is further compounded by low per capita Federal government expenditures on health at US\$2. ${ }^{[19]}$ The issue of cost of ITN found in this study agrees with the findings in other national and international studies. ${ }^{[12,14,16,20]}$

\section{Study limitations}

The study has not investigated the knowledge of net re-treatment and its efficacy among students. Since repeated washing of the nets makes them lose potency. However, it is likely that this will not affect the findings of this study as the nets do not easily loose the chemicals and the respondents did not cease using them.

\section{Conclusion}

Knowledge and awareness, of ITNs was quite high among the respondents, sadly, the reverse was the case in terms of current usage. As malaria scourge is still a very serious public health problem in the country, there is need for increased public awareness campaigns through information, education and communication (IEC) by posters, leaflets, etc. To meet the RBM target and millennium development goals (MDGs) on malaria, all three tiers of Governments need to make ITNs available, affordable, and sustainable. ITN usage among boarding school pupils should be incorporated into school health service.

Finally, there is need to ensure efficient and effective distribution networks for easy access.

\section{Recommendations}

A major problem, though not considered in this study is the issue of re-treatment of ITNs and their efficacy.

There is also the issue of consistent and regular net usage, as during the peak season of malaria, people are keen to use the nets to avoid bites but they may not use them consistently at other times. All these problems need to be addressed.

Generally, like other public health programmes is the issue of ITN sustainability. If a community is supplied with ITNs and taught how to use them, will people continue using the nets, purchasing the insecticide for re-treatment and replacing old/torn nets when necessary?

Finally, it has been noted that most clinicians maintained that their job was to treat malaria and not to control mosquitoes. ${ }^{[22]}$ This is very worrisome. Therefore, all members of the health team should know more about ITNs and be in a position to encourage their use.

\section{Acknowledgements}

Our sincere appreciation goes to Maji C.S. and Sufyan I. for their assistance in data collection and late Dr Eni, R. $\mathrm{N}$. for his useful suggestions.

\section{References}

1. WHO- Roll Back Malaria fact sheet: Malaria- A global crisis. Geneva: WHO; 2000

2. FGN/WHO/UNICEF/UNDP/World Bank. African submit on roll back malaria fact sheet. Abuja, Nigeria: 24-25 April, 2000.

3. Statistical Year Book of Kaduna State 1996 Edition. Ministry of Finance and Economic planning, Statistics and Research Dept.1996. p. 164-203.

4. WHO Guidelines on the use of insecticide-treated mosquito nets: For the prevention and control of Malaria in Africa. Trial ed, 2001. p. 1-8.

5. FMOH. Malaria Epidemiological Profile - Nigeria (adopted from Mara Arma 1995 and WHO-RBM (19951997).

6. $\mathrm{FMOH}$. Malaria Control in Africa in the New Millennium. Abuja: FMOH. 2000

7. Blagoveschensky D, Bregetova N, Monchadsky A. An investigation of new repellants for the protection of man against mosquito attacks. Trans Royal Soc Trop Med Hyg 1945;34:147-50.

8. Malaria Supplement: Africa Health. Sept 2000. p. 18-20.

9. UNICEF. Rolling Back Malaria. New York: UNICEF; 1999

10. Amajo CN. ITN for malaria Control in Nigerian communities: In ESN-Insects and Man in the new Millennium. The Nigerian perspective (an occasional publication); 2002. p. 120.

11. WHO. Roll Back Malaria: Specifications for Netting materials. Report of an Informal Consultation. Geneva: WHO; 8-9 June 2000. p. 3-8.

12. Aniefiok M. Acceptance and use of insecticide treated 
bednet (ITN) in the Roll Back Malaria Programme in Kuje Area Council, Abuja.J Environ Health2005;2:26-33.

13. Brieger WR, Onyido AE, Sexton JD, Ezike VI, Breman JG, Ekanem OJ. Monitoring community response to malaria control using insecticide impregnated bed nets, curtains and residual spray at Nsukka, Nigeria. Health Educ Res Theory and Practice 1996;11:133-45.

14. Jones C. Bed nets and malaria. Postgrad Doctor 2002;24:23-5.

15. I Iboudo-Sango E, Cuzin-Ouattara N, Diallo A, Cousens SN, Esposito F, Habluetzel A, et al. Insecticide-treated materials, mosquito adaptation and mass effect: Entomological observations after five years of vector control in Burkina Faso. Trans Royal Soc Trop Med Hyg 2001:95:353-60.

16. Insecticide-treated Nets. New findings from Kenya, published by Centers for Disease Control and Prevention (CDC). Atlanta, USA, Confirm effectiveness in areas of intense transmission. Africa Health (Mera) July 2003, issue 6

17. Williams JE. Integrated vector management of Malaria. MERA. 2004. Issue 14: p. 3-4.

18. Moses AJ. Evaluation of Environmental aspect of HIV/ AIDS Prevalence in Abuja and its implication for IEC. 2004 in press.

19. UNEP. Poverty and the environment. Nairobi: UNEP; 1995.

20. WHO and UNICEF. The African Malaria Report 2003. Geneva: WHO.

21. Chinnock P. Malaria control programmes: Are ITNs the way forward. Africa Health 1999;21:12-3.

Page $\mid 89$

Source of Support: Nil, Conflict of Interest: None declared.

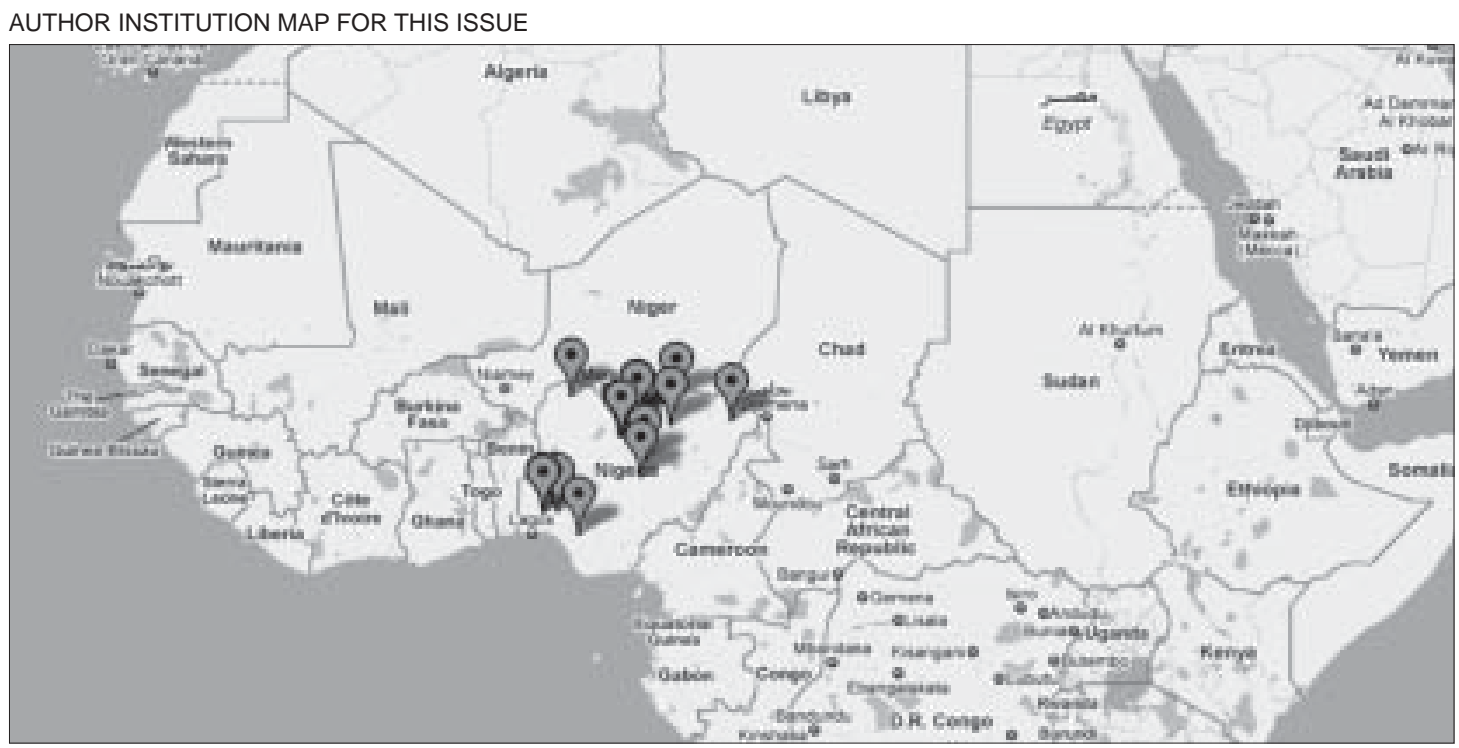

Please note that not all the institutions may get mapped due to non-availability of requisite information in Google Map. For AIM of other issues, please check Archives/Back Issues page on the journal's website. 